\title{
Meu ABC: uma aplicação multimédia para alfabetização contextualizada
}

\author{
Rivanildo S. dos Santos, Josimar A. A. Junior, Rháleff N. R. Oliveira, Yuska P. C. \\ Aguiar \\ Departamento de Ciências Exatas (DCX) - Universidade Federal da Paraíba (UFPB) \\ Caixa Postal: 58297-000 - Rio Tinto - PB - Brasil \\ \{rivanildo.silva, josimar.alves, rhaleff.nascimento, \\ yuska\} @dcx. ufpb.br
}

Resumo. Este artigo apresenta o protótipo do aplicativo Meu $A B C$, desenvolvido para auxiliar o processo de alfabetização de crianças, por meio da correspondência das letras com sons e imagens, de acordo com o contexto histórico-social do usuário. O aplicativo permite que os usuários sejam além de consumidores, produtores das mídias que serão apresentadas.

\section{Cenário de uso}

Aprender a ler e escrever é uma tarefa complexa e exige várias habilidades, como o conhecimento das letras e sua correspondência com os sons da linguagem, conforme Souza (2013). Além disso, ainda é necessário que as crianças saibam associar as letras com os sons e imagens de acordo com o contexto regional, cultural, social no qual está inserido. Alfabetizar é muito mais do que ler palavras; é propiciar a "leitura do mundo", o mundo da criança, entendem Auler e Delizoicov (2001).

Para Almeida (2012), o processo de alfabetização com o auxílio do computador é possível, pois abre possibilidade para que os alunos tenham uma nova e eficaz maneira de ler o mundo cultural. Afinal, o uso da informática na educação estimula o desenvolvimento da autonomia, curiosidade e criatividadevg promovendo a construção de conhecimento da criança.

Dentre as inúmeras possibilidades da utilização da informática na educação, a multimídia é uma das áreas mais promissoras, segundo Silveira (1999). Multimídia é qualquer combinação de texto, arte gráfica, som, animação e vídeo transmitidos pelo computador, afirma VAU apud Silveira (1999).

"A multimídia transforma os estudantes de receptores passivos de informação em participantes ativos em um processo de aprendizagem rico em meios." (Silveira, 1999, pg. 28)

Com o fito de ser um facilitador na construção de conhecimento, é apresentado o protótipo do aplicativo em Android Meu ABC, desenvolvido para apoiar o processo de alfabetização. O Meu ABC é uma aplicação multimédia, pois possibilita inserir o som (gravar áudio) e uma imagem relacionada à letra. Segundo Santos apud MAYER (2001), os alunos aprendem melhor quando se combinam palavras e imagens, do que no momento em que se usam somente palavras. 
O presente trabalho está estruturado em 4 seções. A seção 2 apresenta o processo de desenvolvimento adotado e as tecnologias utilizadas para o desenvolvimento do software e na seção 3 é apresentada a descrição do software com as principais telas. Por fim, são apresentadas na seção 4 as considerações finais, com a descrição das contribuições e principais resultados.

\section{Desenvolvimento}

O aplicativo foi desenvolvido na Plataforma Android e foi usado a linguagem de programação Java 8 para a implementação do aplicativo e a linguagem de marcação XML para ser criado a interface do usuário (UI). Todo o desenvolvimento se deu através do Ambiente de Desenvolvimento Integrado (IDE, na sigla em inglês) Android Studio 1.5.1 (https://developer.android.com/studio/index.html).

Não utilizamos nenhum modelo de processo para o desenvolvimento da aplicação, pois foi um projeto simples. Tivemos uma equipe pequena e o escopo era reduzido.

A escolha da plataforma Android se deu pelo fato de ser a mais utilizada dentre os dispositivos móveis no Brasil. De acordo com Alvim (2015), celulares com sistema operacional Android se mantiveram na liderança absoluta de vendas no Brasil no último trimestre de 2015. Em dezembro, a participação de mercado terminou assim: 91,8\% para Android; 5,1\% para Windows; 2,8\% para iOS; 0,2\% para "Outros"; e nada para BlackBerry.

O aplicativo foi desenvolvido na API 17 para Min Sdk Version 4.2, ou seja, para versão mínima 4.2 do Android. Sendo assim o aplicativo funciona apenas para versões iguais ou superiores à 4.2. Escolhemos esta versão porque as tecnologias que necessitávamos para a construção do aplicativo só existiam a partir da 4.2, que também é conhecida como JellyBean.

Criamos o primeiro release do $\mathrm{Meu} \mathrm{ABC}$ e distribuímos para um pequeno grupo de usuários a fim de identificar possíveis problemas com diferentes tipos de dispositivos móveis e também para obter críticas, dicas e sugestões dos usuários para nossa aplicação. Sendo assim, recebemos do grupo sugestões do posicionamento dos botões na tela, usabilidade do aplicativo, adição de jogos, expansão para ensinar os números, uma tela para a configuração do aplicativo e adição de animações.

Até agora nenhuma função foi adicionada a partir da experiência do grupo que recebeu o release e não houve ainda nenhuma validação do aplicativo com o público alvo. É ainda um protótipo que aos poucos será liberado para validação.

\section{Apresentação do Software}

$\mathrm{O}$ aplicativo Meu ABC fornece ao usuário a possibilidade de personalizar os áudios, gravando direto da aplicação, e as imagens, selecionando através do álbum de fotos do dispositivo, que serão apresentados nas letras do alfabeto. 
V Congresso Brasileiro de Informática na Educação (CBIE 2016)

Anais dos Workshops do V Congresso Brasileiro de Informática na Educação (CBIE 2016)

Para acesso as letras o usuário possui 2 opções: começar a partir da letra A, apenas clicando no botão de play; começar a partir da letra que desejar, apertando no botão de listar as letras e escolher a letra desejada. Podemos observar a tela principal que contém esses dois botões a seguir, na Figura 1.

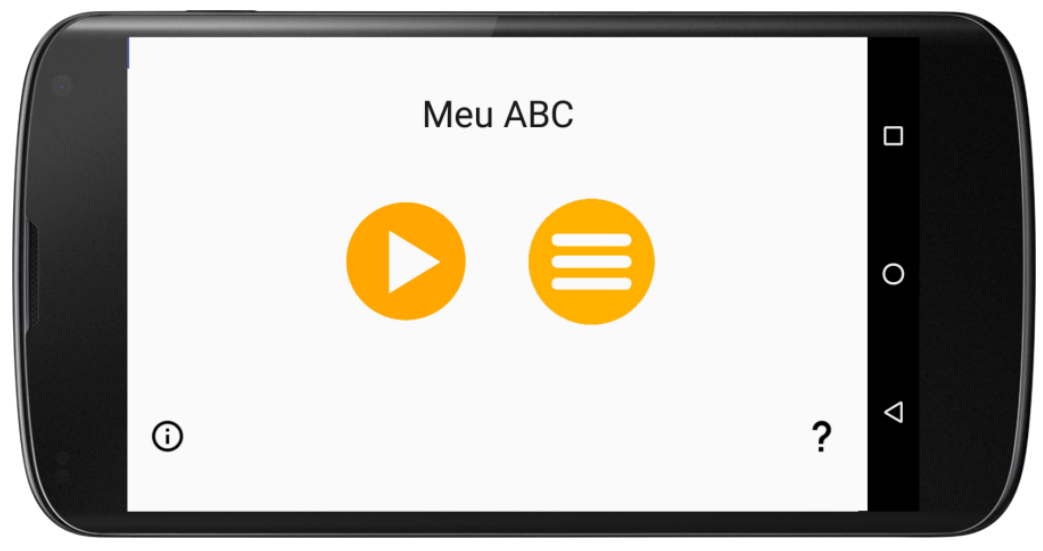

Figura 1: Tela Principal

A tela de apresentação de letras contém botões de navegação para a próxima letra ou a letra anterior. $\mathrm{O}$ texto presente nesses botões corresponde às letras que podem ser apresentadas nas telas seguintes. Apenas para a letra A não é apresentado o botão anterior e apenas para a letra Z não é apresentado o botão de próximo. Na Figura 2, a seguir, temos a representação dessa tela.

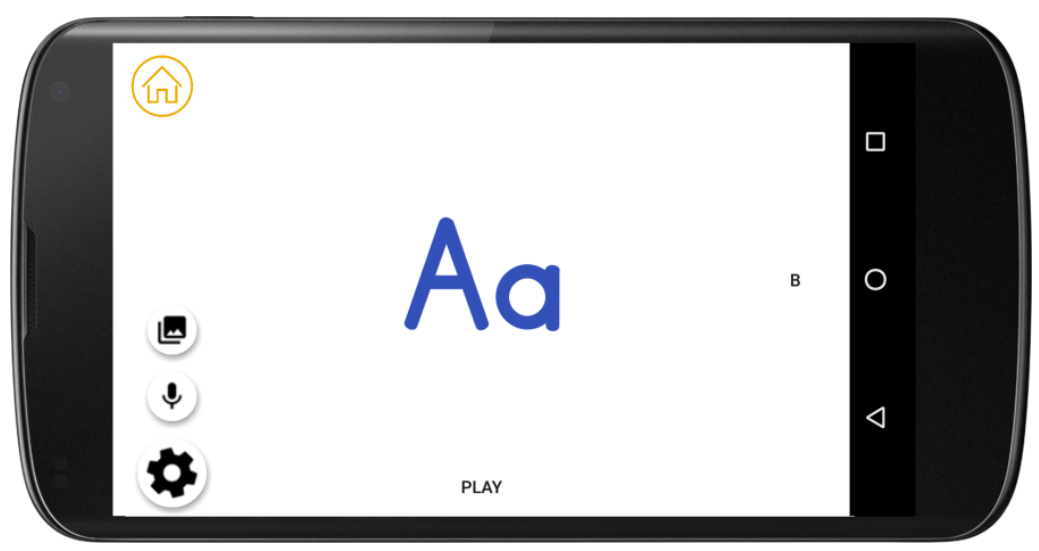

Figura 2: Tela Apresentação das letras

Na tela de apresentação das letras, encontramos um FlatButton com um menu, esse menu se expande ao ser clicado e apresenta 2 opções: gravar áudio ou selecionar imagem. Para gravar o áudio basta clicar no ícone de áudio e em seguida clicar no botão gravar, após gravar o áudio você pode escutá-lo e salvá-lo. Caso não queira é só selecionar o botão cancelar, como pode ser visto na Figura 3. 
V Congresso Brasileiro de Informática na Educação (CBIE 2016)

Anais dos Workshops do V Congresso Brasileiro de Informática na Educação (CBIE 2016)

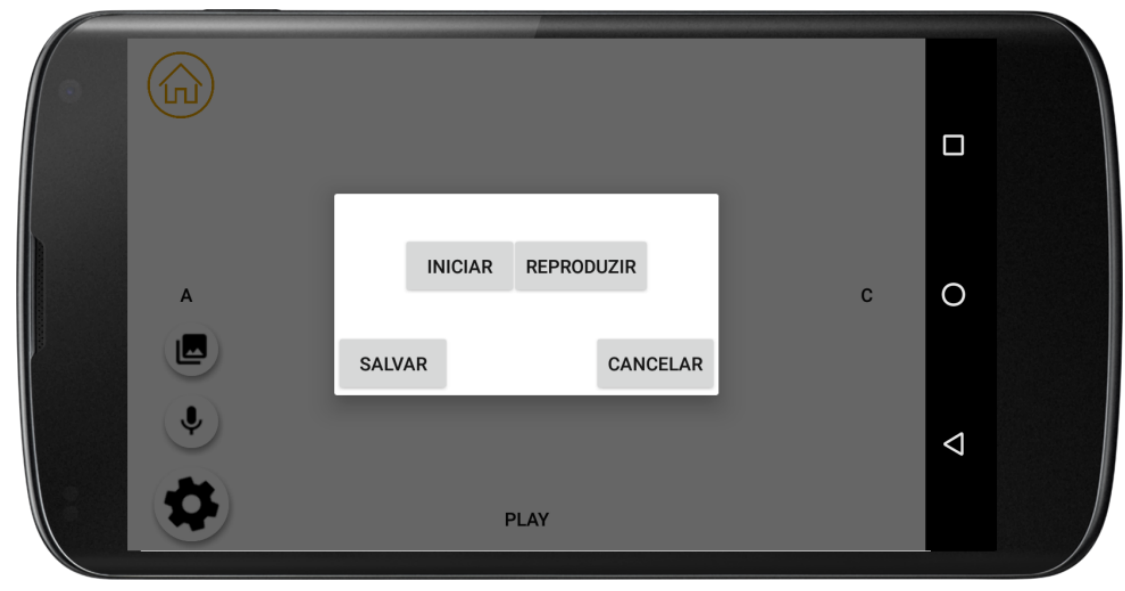

Figura 3: Captura de áudio

Para colocar a imagem basta selecionar o ícone de imagem e, a partir de sua galeria, você escolherá a imagem que deseja salvar. A tela de apresentação das letras ainda possui um botão para voltar à tela principal e um botão para reproduzir o áudio, quando não apresentado.

Para baixar a aplicação acesse: https://goo.g1/g2GSfw

Vídeo demonstrativo encontra-se em: https://youtu.be/ciEEEE--X40

\section{Considerações finais}

Esperamos que com o uso do aplicativo a alfabetização de crianças seja feita considerando o contexto na qual ela está inserida. Que atinja não só o Brasil, mas países lusófonos também.

Como mencionado anteriormente, ainda não implementamos nenhuma modificação das relatadas pelo grupo de usuário que recebeu o release. Em versões futuras, provavelmente, adicionaremos algumas das funções relatadas, como melhorias na interface e adição de uma área para personalizar os áudios e as imagens em uma tela à parte. Após adicionarmos essas funcionalidades pensaremos em validar a aplicação em turmas de alfabetização de crianças.

Pretendemos, futuramente, incluir um jogo com os áudios e as imagens que foram colocados na aplicação, com a finalidade dos usuários testarem seus conhecimentos e, a partir de uma pontuação das atividades, conseguirem enxergar seu processo de aprendizado. Em projetos futuros também queremos criar uma nova versão com adequação de layout para diferentes tamanhos de tela e produzir a aplicação voltada para outros idiomas com arquivos de tradução. 
V Congresso Brasileiro de Informática na Educação (CBIE 2016)

Anais dos Workshops do V Congresso Brasileiro de Informática na Educação (CBIE 2016)

\section{Referências}

Alvim, Mariana. Vendas de celulares com sistema Android e Windows cresceram no Brasil em 2015; IOS teve queda. 01 Jan. 2016. Diponível em: http://blogs.oglobo.globo.com/lauro-jardim/post/vendas-de-celulares-com-sistemaandroid-e-windows-cresceram-no-brasil-em-2015-ios-teve-queda.html. Acesso em: 20 Jun. 2016.

Almeida, F. J. (2012). Educação e informática: os computadores na escola (5a ed.). São Paulo: Cortez.

Auler, D. e Delizoicov, D., “Alfabetização Científico-Tecnológica Para Quê?”, Ensaio Pesquisa em Educação em Ciências, v.3, n.1, junho, 2001.

Souza, J. T. (2013). Mundos das letras: um aplicativo para ensinar o nome e o som das letras a crianças falantes do português do Brasil (Dissertação de Mestrado). Pontifica Universidade Católica de São Paulo, São Paulo.

Silveira, Sidnei Renato. Estudo e Construção de uma Ferramenta de Autoria Multimídia para a Elaboração de Jogos Educacionais. Porto Alegre: PPGC/UFRGS, 1999. Dissertação de Mestrado.

Santos, L. M. A., \& Tarouco, L. M. R. (2007). A importância do estudo da teoria da carga cognitiva em uma educação tecnológica. RENOTE, 5(1). 